\title{
A meta-analysis of the association between gestational diabetes mellitus and chronic hepatitis B infection during pregnancy
}

Dechuan Kong ${ }^{1,2}$, Haiyan Liu ${ }^{3}$, Shan Wei ${ }^{1,2}$, Yan Wang ${ }^{4}$, Anqun Hư ${ }^{3}$, Wenhui Han ${ }^{4}$, Naiqing Zhao ${ }^{5}$, Yihan $\mathrm{Lu}^{1,2^{*}}$ and Yingjie Zheng ${ }^{1,2,6^{*}}$

\begin{abstract}
Background: Chronic hepatitis B (CHB) infection during pregnancy is associated with insulin resistance. A meta-analytic technique was used to quantify the evidence of an association between $\mathrm{CHB}$ infection and the risk of gestational diabetes (GDM) among pregnant women.

Methods: We searched PubMed for studies up to September 5th 2013. Additional studies were obtained from other sources. We selected studies using a cohort-study design and reported a quantitative association between CHB infection during pregnancy and risk of GDM. A total of 280 articles were identified, of which fourteen publications involving 439,514 subjects met the inclusion criteria. A sequential algorithm was used to reduce between-study heterogeneity, and further meta-analysis was conducted using a random-effects model.

Results: Ten out of the fourteen studies were highly homogeneous, indicating an association of 1.11 [the adjusted odds ratio, 95\% confidence interval 0.96 - 1.28] between CHB infection during pregnancy and the risk of developing GDM. The heterogeneity of the additional four studies may be due to selection bias or possible aetiological differences for special subsets of pregnant women.
\end{abstract}

Conclusions: These results indicate that CHB infection during pregnancy is not associated with an increased risk of developing GDM among pregnant women except those from Iran.

Keywords: Chronic hepatitis B infection, Gestational diabetes mellitus, Pregnant women, Meta-analysis

\section{Background}

The hepatitis B virus (HBV) accounts for significant morbidity and mortality worldwide [1]. An estimated one-third of the worldwide population has been exposed to HBV, and 400 million people are chronic carriers [1]. HBV can be transmitted vertically, sexually, and through other routes, and pregnant women play important roles in each of those transmission routes. Chronic hepatitis B $(\mathrm{CHB})$ infection during pregnancy often results in hepatic flare [2] and possibly other adverse outcomes [3-17], including gestational diabetes mellitus (GDM)

\footnotetext{
* Correspondence: luyihan@fudan.edu.cn; yjzheng@shmu.edu.cn

'Department of Epidemiology, School of Public Health, Fudan University, Shanghai 200032, China

${ }^{2}$ The Key Laboratory on Public Health Safety, Ministry of Education, Fudan University, Shanghai 200032, China

Full list of author information is available at the end of the article
}

[3-8,10-13,15-17], although conflicting evidence exists on this last point.

GDM is defined as glucose intolerance with an onset or first recognition during pregnancy. Asian women, including Chinese women, have been found to have the highest incidence of GDM [18]. Women with GDM are at an increased risk for adverse perinatal and maternal outcomes including macrosomia, caesarean section, birth trauma, and diabetes later in life, although treatment significantly decreases these risks [19]. Until now, liver disease of various aetiologies has been implicated as a cause of diabetes [20], and chronic hepatitis $C$ virus $(\mathrm{CHC})$ infection has been established to increase the risk of diabetes mellitus (DM) [21].

Similarly to CHC infection, $\mathrm{CHB}$ infection is considered to be associated with insulin resistance (IR) [22], which implies that it may increase the risk of developing 
DM and/or GDM. However, the association between $\mathrm{CHB}$ infection and the risk of DM and/or GDM remains less convincing. An increased risk was reported for DM only by Li-Ng [23], but this result was not confirmed by a recently published ten-year cohort study [24]. Several studied have reported an increased risk for GDM $[4,6,7,10,11]$, but this result was contradicted by many others [3,5,8,9,12-17]. Due to the limited resources and time available for $\mathrm{HBV}$ vaccination, the prevalence of $\mathrm{CHB}$ infection among pregnant women remains high, especially in HBV epidemic areas such as China [25].

To address these issues, we performed a meta-analysis of cohort studies to investigate whether $\mathrm{CHB}$ infection during pregnancy is associated with an increased risk of GDM.

\section{Methods}

\section{Data sources and search strategy}

This meta-analysis was conducted in compliance with the Meta-Analysis of Observational Studies in Epidemiology guidelines (http://edmgr.ovid.com/ong/accounts/ moose.pdf). Two independent investigators (Kong and Liu) searched PubMed from 1966 to September 5th, 2013 using the combinations of terms "hepatitis B" or "hepatitis B surface antigen (HBsAg)" and "pregnancy outcome" or "prenatal outcome" or "perinatal outcome" or "gestational diabetes". We sifted through potentially relevant articles, firstly by titles and abstracts, and then we retrieved the full texts of articles for detailed review. Further, we scanned the reference lists of the articles that met the inclusion criteria in our analysis, and searched for those articles or citations in the Web of Knowledge, Google Scholar and Google to obtain additional studies.

\section{Inclusion and exclusion criteria}

Articles were included if they used a cohort design and reported a quantitative association between $\mathrm{CHB}$ infection during pregnancy and the risk of GDM among pregnant women versus a non-CHB control group. For studies that enrolled overlapping pregnant women, only more recently published studies and/or those with larger sample sizes were included.

Studies included in this analysis defined CHB infection status during pregnancy by the presence or absence of hepatitis B surface antigen (HBsAg) in blood during the first prenatal care visit, on admission to the labour ward, or before delivery. GDM diagnosis was performed according to the recommended clinical practice.

\section{Data extraction}

A form designed a priori was used to extract the information from the included studies. Two independent investigators (Han and Wei) performed the data extraction. A third investigator (Wang) examined the results, and a consensus was considered as agreement between at least two out of the three investigators. GDM was the primary outcome measure. We extracted the following data (Table 1): authors' name, journal and year of publication, country of origin, enrolment period, incidence of GDM in pregnant women who had $\mathrm{CHB}$ infection and those who did not, general characteristics of pregnant women, unadjusted and/or adjusted effect size and the adjusted variables if available.

\section{Assessment of methodological quality}

Two independent investigators (Kong and $\mathrm{Hu}$ ) evaluated the quality of each study using the Newcastle-Ottawa Quality Assessment Scale (NOS) [26]. The third investigator $(\mathrm{Lu})$ examined the results, and a consensus was considered as agreement between at least two out of the three investigators (Table 1). We did not consider the 2nd item of the NOS scale (Was follow-up long enough for outcomes to occur) or the 3rd item (Adequacy of follow up of cohort) because the final outcomes of all pregnant women were followed up to their delivery dates. We defined studies with $\mathrm{NOS} \geq 7$ as high quality and those with $\mathrm{NOS}<7$ as low quality.

\section{Statistical analysis \\ Effect measurement: odds ratio and its adjustment}

The cross-study effect of $\mathrm{CHB}$ infection vs. non-CHB control on the risk of GDM was measured using the odds ratios (OR) with 95\% confidence intervals (CIs), which were reported as the effect measurements in all of the included studies except for one [4], which reported relative risk.

The adjusted OR $\left(\mathrm{OR}_{\mathrm{a}}\right)$ was automatically included in our analysis; the unadjusted or crude $\mathrm{OR}\left(\mathrm{OR}_{\mathrm{c}}\right)$ was corrected using external estimates of confounding by the method of coefficient adjustment introduced by Greenland [27]. Briefly, the confounding effect $U=O R_{c}$ / $\mathrm{OR}_{\mathrm{a}}$ was calculated by an external study. The variance of $U$ was estimated using the formula $V_{u}=V_{a}-V_{c}$, where $V_{a}$ and $V_{c}$ are the variances of the natural logarithm of the $\mathrm{OR}_{\mathrm{c}}$ and $\mathrm{OR}_{\mathrm{a}}$ from the same study, respectively. Then, we used $U$ and its variance $V_{u}$ for further correction. In our analysis, the $\mathrm{OR}_{\mathrm{c}}$ from the Lobstein study [12] and the Chinese or Thailand studies [3,5,8,9,15-17] were adjusted using the estimates of $\mathrm{U}$ and $\mathrm{V}_{\mathrm{u}}$ from Reddick 2011 [13] and Lao 2007 [7], respectively.

\section{Heterogeneity analysis and its sensitivity analysis}

We used a random-effects model to pool the $\mathrm{OR}_{\mathrm{a}}$ across studies in Stata version 10.0 (Stata Corp). Heterogeneity was first explored by a $X^{2}$ test with a $P$ value $<0.10$ considered statistically significant and then judged visually by a forest plot, funnel plot and 
Table 1 General characteristics and quality scores of the 14 studies included in this meta-analysis

No Author, publication year, design (matched

variables), study site, country, PW (no,

$\begin{array}{cc}\text { Inclusion/exclusion } & \text { Identification of } \\ \mathrm{HBsAg} / \mathrm{GDM}\end{array}$

Baseline comparison between

$\mathrm{HBsAg}+$ and HBsAg- PW

(data retrieval) Similarity

Dissimilarity

1. Wong SF, 1999

PW delivered after 24 GW or babies

$\mathrm{RCS}$, with all HBsAg- as controls

ELISA/Australian Mean age, parity,

NA

pelvic inflammatory disease, STI,

criteria

history of abortion

A

(computer
database)

Princess Margaret Hospital

smoker or illicit drug users, and DM

Hongkong, China

SP $(7105,11.6 \%)$

Jul.1,1996-Aug.31,1998 (6)

2. Lao TT, 2003

$\mathrm{RCS}$, with a sample as controls

Queen Mary Hospital or others

Hongkong, China

SP $(767, N A)$

Over four months (5)

3. To WWK, 2003

RCS, with all HBsAg- as controls

United Christian Hospital

Hongkong, China

AP (13946, 9.72\%)

Jan. 1997-Dec. 2000 (6)

4. Tse KY, 2005

RCS, matched for age and parity

Queen Mary Hospital (section mainly for

high-risk paturients)

Hongkong, China

SP $(3348,7.56 \%)$

Jan. 2000-2002 (7)

PW delivered after 24 GW/AHP(2):

incomplete or contradicting data(152)

ELISA/Australian Age GW at delivery,

criteria BMI, parity, incidence

(computer of non-SP or STIs; no

database) clinical manifestation

of liver disorders or

hepatitis.

NA/incomplete data

LISA/WHO

criteria (medica

record)

$\mathrm{BMI}$, height, weight and

$\mathrm{Hb}$ level at booking, eth

history of stillbirth, IVF

pregnancy, haemoglobin

level at booking, past

medical history

Among the $\mathrm{HBsAg}+$ PW, the weight gain in those with GDM was significant less than those without GDM

\section{$\mathrm{OR}_{\mathrm{c}}=1.89(1.14,3.13)$}

$\mathrm{OR}_{\mathrm{a}}=2.04(1.21,3.44) / \mathrm{Age}$, weight and parity

Among the $\mathrm{HBsAg}$ PW, the weight gain in those with GDM was non-significant less

than those without

GDM.

5. Lao TT, 2007

SP, $99 \%$ of those PW delivered at or after

$\mathrm{RCS}$, with all HBsAg- as controls

24 GW/incomplete data (147)

ELISA/ WHO Age, height, parity and

The HBsAg + PW had

lower weight and $\mathrm{BM}$

with lower prop. of

$\mathrm{OR}_{\mathrm{c}}=1.31(1.08,1.57)$

criteria ${ }^{4}$

history of DM

with lower prop.

$\mathrm{OR}_{\mathrm{a}}=1.24(1.01,1.51) /$

parity, age, BMI, presence 
Table 1 General characteristics and quality scores of the 14 studies included in this meta-analysis (Continued)

\begin{tabular}{|c|c|c|c|c|c|}
\hline Hongkong, China & & \multirow{3}{*}{\multicolumn{2}{|c|}{$\begin{array}{l}\text { database, ICD } \\
\text { coding) }\end{array}$}} & \multirow{3}{*}{$\begin{array}{l}\text { smokers, and with } \\
\text { higher prop. of Asian } \\
\text { origin, married, } \\
\text { unemployed and } \\
\text { history of induced } \\
\text { abortion. }\end{array}$} & \multirow{3}{*}{$\begin{array}{l}\text { of iron deficiency anaemia, } \\
\text { and smoking. }\end{array}$} \\
\hline SP $(14464,8.3 \%)$ & & & & & \\
\hline 1998-2001 (8) & & & & & \\
\hline Lert-amornpong S,2007 & \multirow{6}{*}{$\begin{array}{l}\text { Healthy PW Age 20-39 years old/chronic ill- } \\
\text { ness, non-SP, HIV+, smoker, alcohol drinker }\end{array}$} & \multirow{6}{*}{$\begin{array}{l}\text { ELISA/NDDG } \\
\text { (medical record) }\end{array}$} & \multirow{6}{*}{$\begin{array}{l}\text { Age, weight at booking, } \\
\text { weight gain, hematocrit at } \\
\text { booking, history of } \\
\text { contraception, parity and } \\
\text { past health. }\end{array}$} & \multirow[t]{6}{*}{ NA } & $\mathrm{OR}_{c}=3.04(0.60,15.28)$ \\
\hline RCS, matched for age and date of delivery & & & & & \multirow[t]{5}{*}{$\mathrm{OR}_{\mathrm{a}}=2.89(0.55,15.17)^{*_{1}} / \mathrm{NA}$} \\
\hline Phramongkutklao College of Medicine & & & & & \\
\hline Bangkok,Thailand & & & & & \\
\hline SP $(8515,1.93 \%)$ & & & & & \\
\hline Jan.1, 2003-Dec.31,2005 (5) & & & & & \\
\hline Thungsuk R, 2008 & Healthy PW & \multirow{6}{*}{$\begin{array}{l}\text { ELISA/ADA } \\
\text { (medical record) }\end{array}$} & \multirow{6}{*}{$\begin{array}{l}\text { Age, hematocrit at } \\
\text { booking, parity and past } \\
\text { health }\end{array}$} & \multirow[t]{6}{*}{ NA } & $\mathrm{OR}_{c}=1.39(0.37,5.28)$ \\
\hline $\begin{array}{l}\text { RCS, matched for age, parity and year of } \\
\text { delivery }\end{array}$ & \multirow[t]{5}{*}{$\begin{array}{l}\text { Age 20-39 years old/chronic illness' non-SP, } \\
\text { HIV+, smoker, alcohol drinker }\end{array}$} & & & & \multirow[t]{5}{*}{$\mathrm{OR}_{\mathrm{a}}=1.32(0.33,5.29)^{* 1} / \mathrm{NA}$} \\
\hline Sawanpracharak Hospital & & & & & \\
\hline Nakhonsawan, Thailand & & & & & \\
\hline AP $(2548,1.3 \%)$ & & & & & \\
\hline Jan. 2005-Dec, 2007 (5) & & & & & \\
\hline Saleh-Gargari S, 2009 & \multirow[t]{6}{*}{ SP/AHP } & \multirow{6}{*}{$\begin{array}{l}\text { ELISA/ADA } \\
\text { (medical record) }\end{array}$} & \multirow{6}{*}{$\begin{array}{l}\text { Age, parity, BMl, } \\
\text { hemoglobin level at } \\
\text { admission, past health } \\
\text { history }\end{array}$} & \multirow[t]{6}{*}{ NA } & $\mathrm{OR}_{\mathrm{C}}=4.13(1.96,8.70)$ \\
\hline RCS, matched for age, parity, and BMI & & & & & \multirow[t]{5}{*}{$\mathrm{OR}_{\mathrm{a}}=3.62(1.60,7.90) / \mathrm{NA}$} \\
\hline $\begin{array}{l}\text { the labor ward in Mahdieh and Vali Asr } \\
\text { Tertiary Care Hospital }\end{array}$ & & & & & \\
\hline Tehran, Iran & & & & & \\
\hline$S P(N A, N A)$ & & & & & \\
\hline Mar. 2001-Dec. 2008 (6) & & & & & \\
\hline Aghamohammadi A, 2011 & SP/ & \multirow{6}{*}{$\begin{array}{l}\text { ELISA/ADA } \\
\text { (medical record) }\end{array}$} & \multirow{6}{*}{$\begin{array}{l}\text { Age, parity, haemoglobin } \\
\text { level at booking, past } \\
\text { medical history }\end{array}$} & \multirow[t]{6}{*}{ NA } & $\mathrm{OR}_{\mathrm{c}}=2.34(1.32,4.17)$ \\
\hline $\begin{array}{l}\text { RCS, matched for age and parity, selected at } \\
\text { random }\end{array}$ & \multirow[t]{5}{*}{ AHP } & & & & \multirow[t]{5}{*}{$\mathrm{OR}_{\mathrm{a}}=1.53(1.19,1.97) / \mathrm{NA}$} \\
\hline the labor ward in Imam Khomeyni & & & & & \\
\hline Sari, Iran & & & & & \\
\hline SP $(2953,5.07 \%)$ & & & & & \\
\hline Jan.,2005-Dec.,2008 (6) & & & & & \\
\hline Lobstein S, 2011 & \multirow{3}{*}{$\begin{array}{l}\text { SP (8193)/non-SP (427); HBsAg not } \\
\text { available (887) }\end{array}$} & \multirow{3}{*}{$\begin{array}{l}\text { ELISA/IADPSG } \\
\text { (computer } \\
\text { database) }\end{array}$} & \multirow{3}{*}{$\begin{array}{l}\text { BMI, age, history of } \\
\text { stillbirths, ectopic } \\
\text { pregnancies, IVF } \\
\text { pregnancies }\end{array}$} & \multirow{3}{*}{$\begin{array}{l}\text { The HBsAg + PW had } \\
\text { lower weight and } \\
\text { height, higher prop. of } \\
\text { Asian origin, married, } \\
\text { unemployed, history of }\end{array}$} & $\mathrm{OR}_{c}=2.82(0.17,46.68)$ \\
\hline RCS, with all HBsAg- as controls & & & & & \multirow[t]{2}{*}{$\mathrm{OR}_{\mathrm{a}}=2.20(0.13,37.03)^{*}{ }^{* 1} / \mathrm{NA}$} \\
\hline Gynecological University Hospital & & & & & \\
\hline
\end{tabular}


Table 1 General characteristics and quality scores of the 14 studies included in this meta-analysis (Continued)

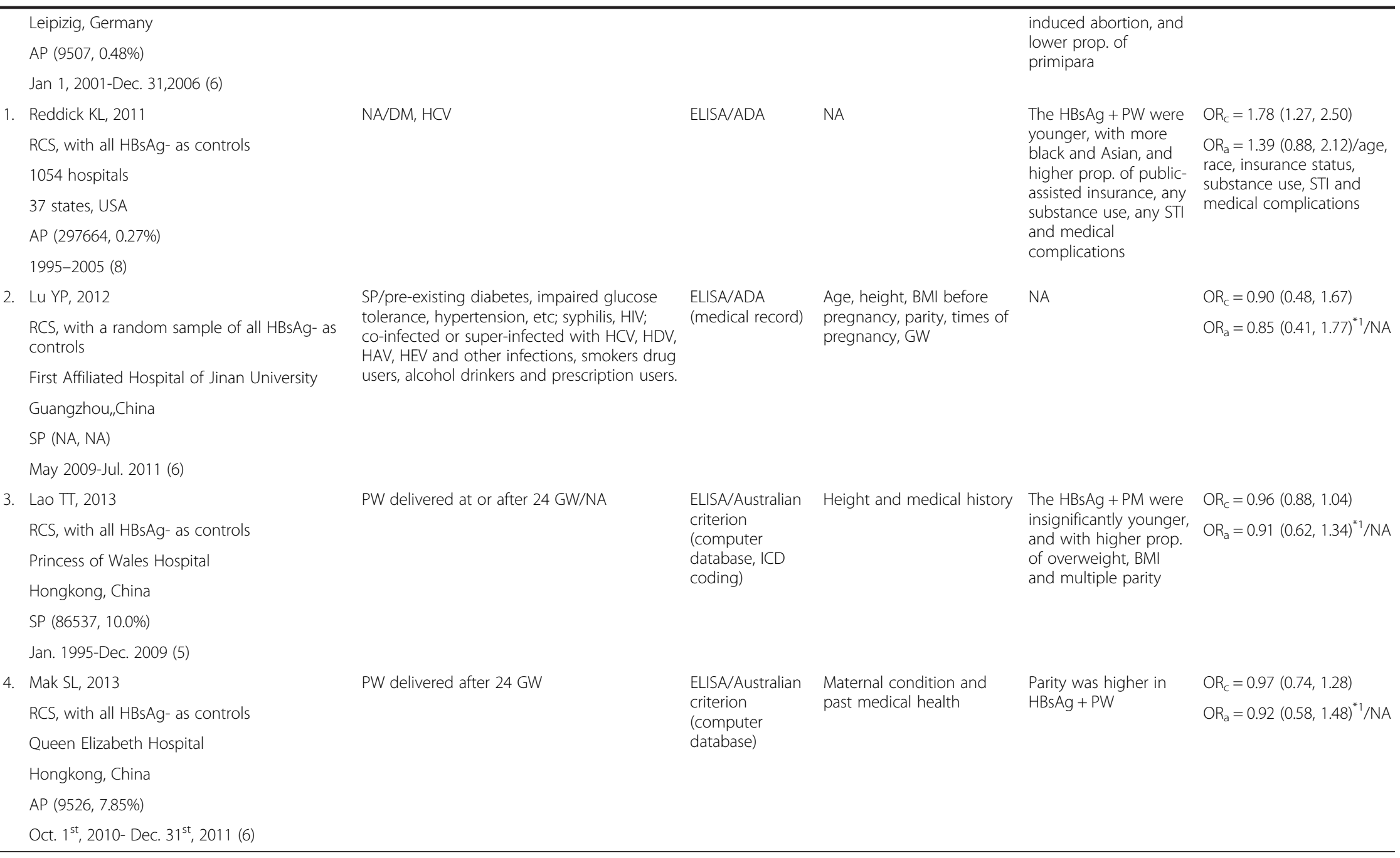

\section{Notes.}

PW: pregnant women; NOS: Newcastle-Ottawa Quality Assessment Scale; no: number; HBsAg: hepatitis B virus surface antigen; GDM: gestational diabetes mellitus; Cl: confidence interval; RCS: retrospective cohort study; SP: single pregnancy; GW: gestational weeks; BW: birth weight; AHP: acute hepatitis during pregnancy; STI: sexually transmitted infection; DM: diabetes mellitus; ELISA: Enzyme-linked immunosorbent assay; NA: not available; $\mathrm{OR}_{c}$ : crude odds ratio; $\mathrm{OR}_{a}$ : adjusted odds ratio; WHO: World Health Organization; BMI: body mass index; OGT: oral glucose tolerance test; $\mathrm{RR}_{\mathrm{c}}$ : crude risk ratio; $\mathrm{RR}_{\mathrm{a}}$ : adjusted risk ratio; $\mathrm{Hb}$ : haemoglobin; IVF: In vitro fertilization; prop: proportion; HIV: human immunodeficiency virus; NDDG: National Diabetes Data Group; ADA: American Diabetes Association; IADPSG: International Association of Diabetes in Pregnancy Study Group; HCV: hepatitis C virus; HDV: hepatitis D virus; HAV: hepatitis A virus; HEV: hepatitis E virus; ICD: International Classification of Diseases.

${ }^{1} \mathrm{O} \mathrm{R}_{\mathrm{a}}$ was calculated using external estimates of confounding by the method of coefficient adjustment. 
Galbraith plot. The extent of heterogeneity was measured by Higgins' $\mathrm{I}^{2}$. We also explored the influence of heterogeneity on the pooled $\mathrm{OR}_{\mathrm{a}}$ across studies using a sensitivity analysis introduced by Patsopoulos [28]. Briefly, for a meta-analysis of $n$ studies, we perform $n$ new meta-analyses where one study is excluded from the calculation each time. The study that leads to the largest decrease in $\mathrm{I}^{2}$ upon exclusion is dropped, and a new set of $n-1$ studies is created. This process is continued until the $\mathrm{I}^{2}$ is decreased to the lowest possible value.

For the heterogeneous studies that were excluded from further analysis, we explored the possible reasons for the heterogeneity using a causal diagram.

\section{The combined effect estimate}

For the homogenous studies, the Dersimonian and Laird random-effects model was used to pool the $\mathrm{OR}_{\mathrm{a}}$ across studies in Stata version 10.0 (Stata Corp). Sub-group analysis and meta-regression were carried out to examine the effect in relation to design, type of epidemic area, article quality and GDM diagnostic criteria. We used the interaction test to estimate the difference between two sub-groups [29]. Publication bias was assessed by a visual inspection of a funnel plot and by the Egger's and Begger's test [30], and a nonparametric trim and fill method was applied if possible [31]. The predictive intervals were calculated using a t-distribution with $\mathrm{k}-2$ degrees of freedom, where $\mathrm{k}$ represents the number of studies [32].

\section{Results}

\section{Literature search}

The literature search retrieved 280 papers, 29 of which were identified as potentially relevant to the current analysis. Further backwards or citation searches produced six additional papers. Only fourteen papers [3-13,15-17] representing fourteen independent studies were included in our analysis. The reasons for exclusion of the other studies are listed in Additional file 1: Figure S1.

\section{General characteristics about the studies included in meta analysis}

The fourteen studies included in the present analysis were published between 1999 and 2013 (Table 1). Two studies each were conducted in Thailand $[8,9]$ and Iran $[10,11]$, one in Germany [12], the United States [13], and mainland China [15], and the other seven in Hong Kong, China [3-7,16,17]. All fourteen were hospital-based retrospective cohort studies.

The CHB infection status was determined by the presence or absence of HBsAg during pregnancy, and the diagnosis of GDM was determined through routine clinical practices. This information was retrieved directly from medical records or indirectly from medical records based on a computerised database through the International Classification of Diseases codes.

\section{Heterogeneity analysis and its sensitivity analysis}

The high heterogeneity of the $\mathrm{OR}_{\mathrm{a}}$ across the fourteen studies was demonstrated by visual observation of the forest plot, funnel plot, and Galbraith plot and further verified by the Higgins' $\mathrm{I}^{2}$ value of $58.9 \% \quad\left(\chi^{2}=31.6\right.$, $\mathrm{df}=13, p=0.003$ ).

$\mathrm{I}^{2}$ was reduced by removing one study at a time using a random-effects model based sequential algorithm [28]. As seen from Figure 1a-d, removing one study each time led to a gradual decrease in the Tau-squared value with decreasing $\mathrm{I}^{2}$, and the $95 \%$ CIs of the pooled $\mathrm{OR}_{\mathrm{a}}$ across studies became narrower, with the means, lower and upper 95\% CIs ranging from $1.00-1.40,0.82-1.13$, and $1.21-1.78$, respectively. Actually, 38\% of the $95 \%$ lower CIs were below 1.0 during this process.

After four studies were removed (Lao 2003 [4], SalehGargari 2009 [10], Tse 2003 [6] and Aghamohammadi 2011 [11]), the remaining ten studies were highly homogeneous, with a Higgins' $\mathrm{I}^{2}$ value of $0.0 \%\left(\chi^{2}=8.06\right.$, $\mathrm{df}=9, p=0.53$, Figure 2) and a Tau-squared value of 0.0 .

\section{The combined effect estimate}

The ten highly homogeneous studies involved $99.4 \%$ $(436,991 / 439,514)$ of the subjects among the fourteen studies, and together reported a GDM prevalence of $6.30 \%(884 / 14,028)$ among pregnant women with $\mathrm{CHB}$ infections and 3.63\% (15,352/422,963) among uninfected pregnant women. The association between $\mathrm{CHB}$ infection during pregnancy and the risk of developing GDM was 1.11 [the adjusted odds ratio $\left(\mathrm{OR}_{\mathrm{a}}\right), 95 \%$ CIs: 0.96 1.28, 95\% predictive intervals 0.94 - 1.31] (Figure 2). These findings suggest that $\mathrm{CHB}$ infection during pregnancy does not increase the risk of GDM, in agreement with all of the individual studies except for one [7], which suggests that $\mathrm{CHB}$ infection during pregnancy is associated with a higher risk of GDM.

Subgroup and meta-regression analysis showed that the pooled $\mathrm{OR}_{\mathrm{a}}$ across studies could not be modified by the following characteristics: quality of papers (high vs. low), designs (all non-CHB pregnant women as controls vs. an unmatched or matched sample of non-CHB pregnant women as controls), epidemic levels (high, middle vs. low), and GDM diagnostic criteria.

Visual inspection of the funnel plots of the $\mathrm{OR}_{\mathrm{a}}$ from the ten studies demonstrated a possible publication bias. After trim and fill methods were performed, the pooled OR $_{\mathrm{a}}$ was 1.10 (95\% CIs: 0.96 - 1.26; 95\% predictive intervals: $0.94-1.30$ ) (Figure 3 ). 


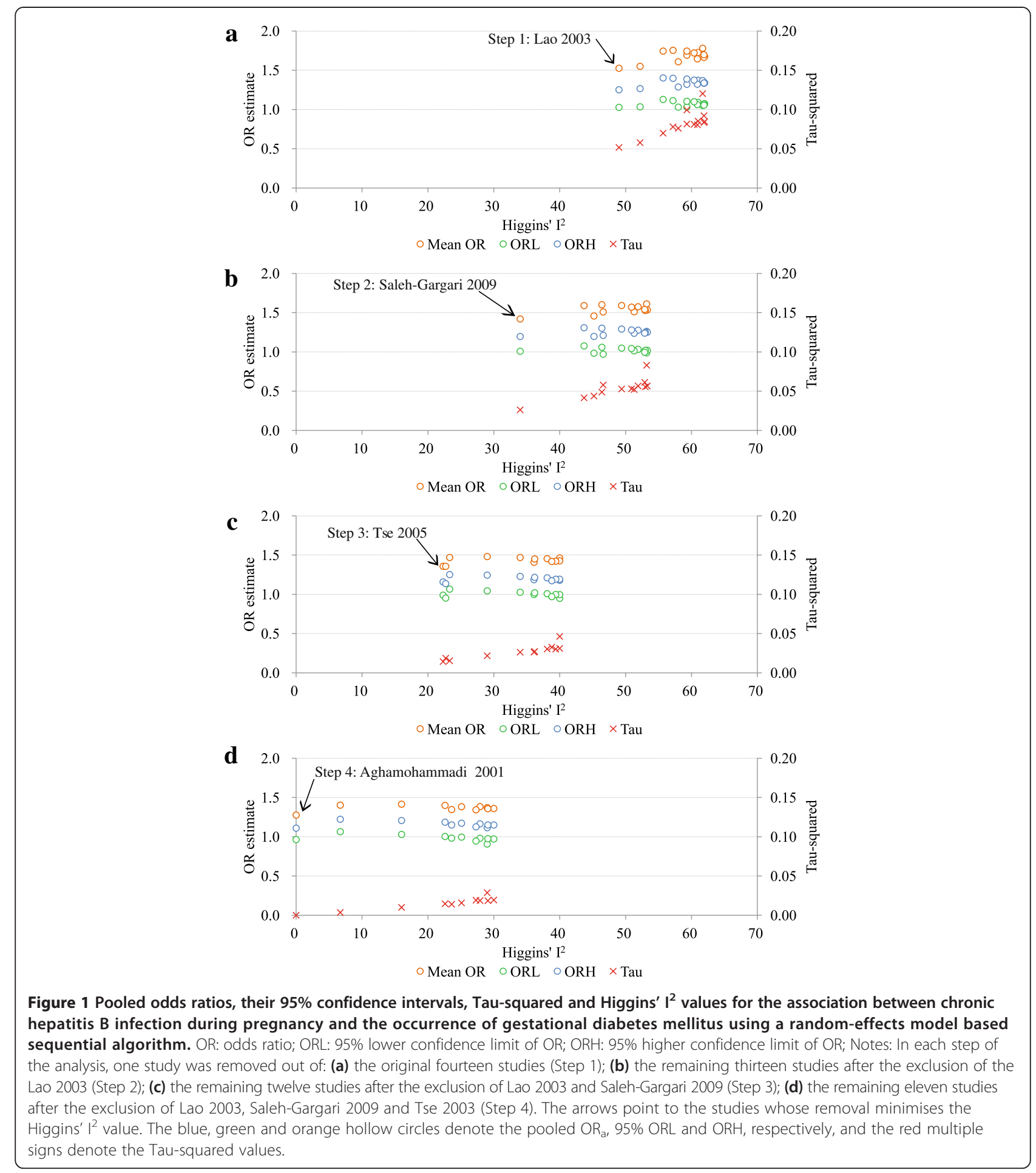

\section{Possible reasons for the heterogeneity of the remaining} four studies

The four heterogeneous studies that were excluded from further analysis all reported a higher risk of GDM for pregnant women with $\mathrm{CHB}$ infection (Figure 2). The effect of their removal on the heterogeneity was depicted within a causal diagram (Figure 4). The first and third excluded studies, Lao 2003 [4] and Tse 2003 [6], respectively, had both recruited a special subset of pregnant women from the population in Hong Kong, China. For the former study, $\mathrm{CHB}$ infected pregnant women were subjected to more rigorous oral glucose tolerance testing 


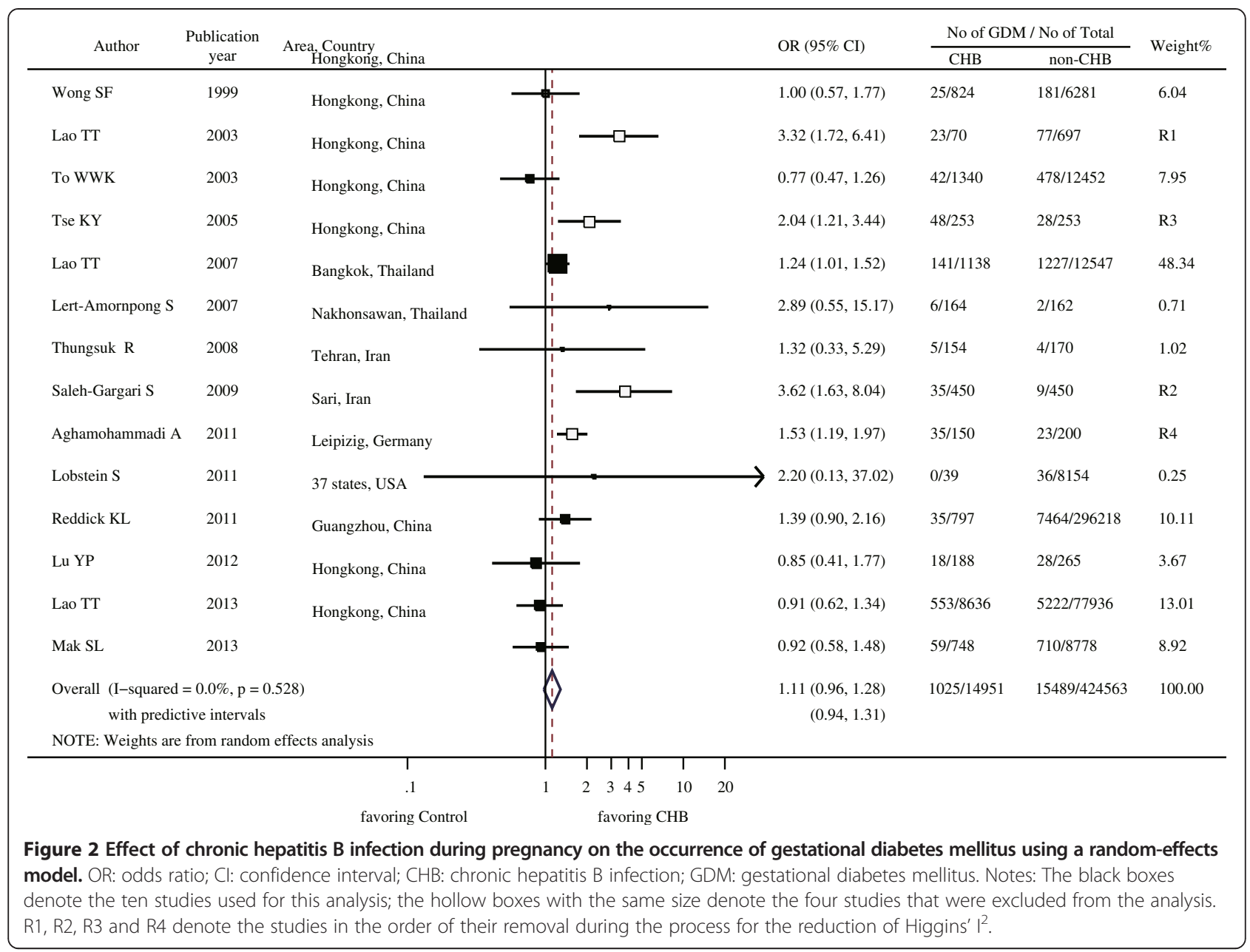

(OGTT), and exhibited a higher serum ferritin concentration which was considered to be both an outcome of the CHB infection and a risk factor of GDM [33]. The pregnant women in the latter study had multiple risk factors, with some suffering from significant medical diseases requiring active treatment, including pre-existing diabetes mellitus. Both $\mathrm{CHB}$ infection during pregnancy and GDM may lead to a high-risk status among pregnant women, which would affect their recruitment into the study. Thus, both studies may have enrolled more CHB infection-related GDM [34], a selection bias resulting in the overestimation of the association between $\mathrm{CHB}$ infection and GDM. The second and fourth excluded studies, Saleh-Gargari 2009 [10] and Aghamohammadi 2009 [11], respectively, were both conducted in Iran with similar designs. As we know, the prevalence of both $\mathrm{CHB}$ infection and GDM differs among ethnic groups [18], making it possible that the CHB infection-GDM association may exist in pregnant Iranian women but not the others. These issues should be addressed further in future studies.

\section{Discussion}

Our results suggest that $\mathrm{CHB}$ infection during pregnancy does not represent a significant general risk for the development of GDM as compared to non-CHB infected controls.

The high initial between-study heterogeneity in this meta-analysis prevented us from drawing strong conclusions. To overcome this problem, we firstly used a sequential algorithm based sensitivity analysis of betweenstudy heterogeneity [28], which differentiated those homogenous studies from the other heterogeneous ones. This strategy was helpful in identifying and sequentially excluding the heterogeneous studies, i.e., at least those with outliers, which made the analysis based on the random-effects model more reasonable [32]. Although the acceptable level of heterogeneity remains unknown [35], we were conservative and chose the lowest Higgins' $\mathrm{I}^{2}$ as our standard for this differentiation. As a result, this strategy resulted in a parallel decrease in both Higgins' $\mathrm{I}^{2}$ and Tau-squared, with values approaching $0.0 \%$ and 0.0 , respectively. 


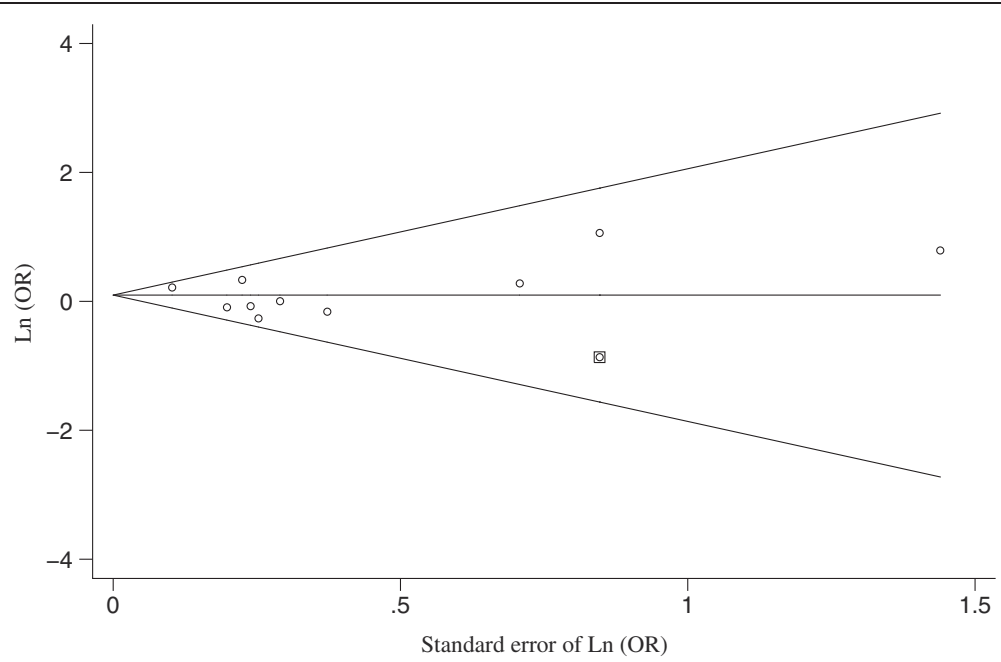

Figure 3 The Egger's funnel plot with pseudo 95\% confidence limits for the ten homogenous studies analysing the effect of chronic hepatitis B infection during pregnancy on the occurrence of gestational diabetes mellitus by using trim and filled methods. OR: odds ratio; Ln: natural logarithm. The hollow circles with or without enclosed boxes represented the original and filled studies, respectively.

Finally, we differentiated ten homogenous studies from the remaining four heterogeneous ones.

Those ten homogeneous studies reported GDM prevalences of $6.30 \%$ and $3.63 \%$ among pregnant women with and without $\mathrm{CHB}$ infection, respectively. The risk of GDM for CHB-infected pregnant women was comparable to the risk for uninfected women $\left(\mathrm{OR}_{\mathrm{a}}=1.11,95 \%\right.$ CI: 0.96-1.28). These findings suggest that $\mathrm{CHB}$ infection during pregnancy is not associated with an additional risk of GDM.

Two of the heterogeneous studies, Lao 2003 [4] and Tse 2003 [6], provided further support. The study of Lao 2003 [4] enrolled pregnant women with higher levels of ferritin, which independently predicts the severity or advanced fibrosis of non-alcoholic fatty liver disease [36]. The study of Tse 2003 [6] enrolled high-risk pregnant women. Thus, both of these studies may have enrolled women with more progressive stages of $\mathrm{CHB}$ infection, which would have resulted in the overestimation of the association between CHB infection and GDM.

It remains unclear why only Iranian pregnant women with $\mathrm{CHB}$ infection appear to have an increased risk of GDM. Both Iranian studies, Saleh-Gargari 2009 [10] and Aghamohammadi 2011 [11], were conducted on Iranian pregnant women with similar designs $[10,11]$ but reported a significantly higher association between $\mathrm{CHB}$ infection and GDM than the other studies analysed here. Since the occurrence of both $\mathrm{CHB}$ infection and GDM differs

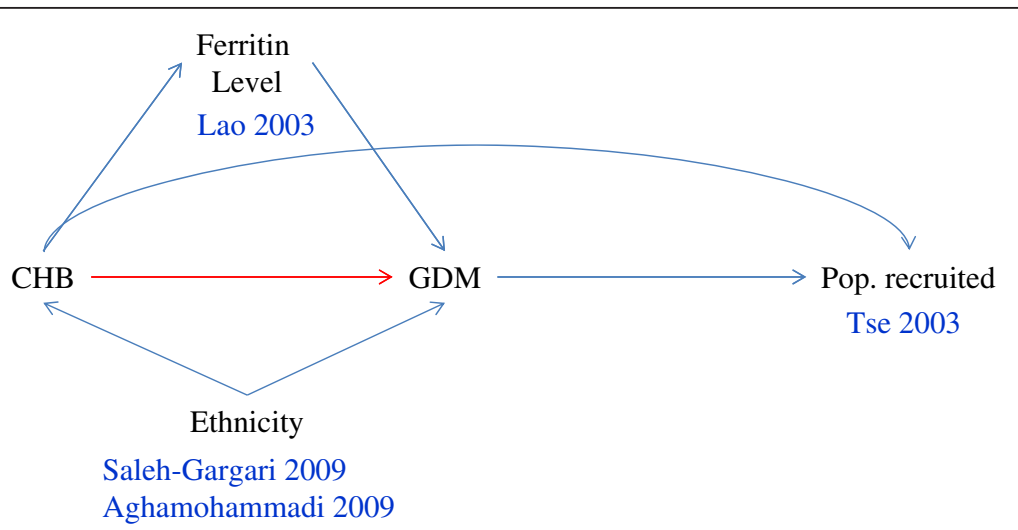

Figure 4 Possible causal diagram related to the four excluded studies analysing the relationship between chronic hepatitis B infection during pregnancy and gestational diabetes mellitus. CHB: chronic hepatitis B infection; GDM: gestational diabetes mellitus; Pop: population. The arrow represents a causal relationship between the two variables at both edges of the arrow. The variable that the arrow points to denotes the outcome of the variable at the other end of the arrow. The red arrow denotes the relationship under study. The blue arrow lines denote the other variables that could affect this relationship. The author names and publication years are associated with the variables as appropriate. 
among ethnic groups [18], there may be an ethnic difference in the association between CHB infection and GDM.

GDM is characterised by pancreatic $\beta$-cell dysfunction that results in insulin resistance (IR). IR has been shown to be associated with both $\mathrm{CHC}$ and $\mathrm{CHB}$ infection [22], but $\mathrm{CHC}$ related IR was mainly due to steatosis development [37] or fibrosis progression [38], which seems to be insignificant for $\mathrm{CHB}$ infection as most pregnant women with $\mathrm{CHB}$ infections are asymptomatic or experiencing mild hepatic injury [39].

Routine screening for GDM is recommended near the beginning of the third trimester, and the identification of GDM will depend on the diagnostic criteria and guidelines. For economic, psychological and other reasons, GDM screening is conducted using a risk factor-based selective screening approach in most countries rather than universal screening. These differences in strategies did not seem to affect the non-significant association between CHB infection and the risk of GDM [12-14,16,17], which was further supported by our sub-group and meta-regression analysis. Only one out of the ten homogenous studies reported a positive association between $\mathrm{CHB}$ infection and the risk of GDM [7]. This difference can be explained by the fact that the replacement of the Australian standard for GDM diagnosis with the WHO standard would have resulted in the inclusion of individuals with impaired glucose tolerance into the GDM group. Routinely, pregnant women will receive the same screening and are subjected to the same diagnostic criteria in the same study regardless of $\mathrm{CHB}$ infection status, so issues of this type seem to play insignificant roles in most of the studies $[3,5,8,9,13,14,16,17]$. Future studies should use a universal screening strategy together with the new diagnostic criteria established for GDM.

\section{Conclusions}

Our findings imply that GDM is not attributable to $\mathrm{CHB}$ infection during pregnancy. Thus, any extra GDM screening for this population is not necessary, which is a commonly accepted practice throughout the world except in Hong Kong, China. This extra screening will likely result in a greater economic burden and additional psychological concerns such as fear or guilt, especially in epidemic areas, like China. Probably, advanced clinical stages of liver diseases of varied aetiologies may be more important in the development of GDM, and the significantly high association between $\mathrm{CHB}$ infection and GDM in Iranian pregnant women is worth further study.

\section{Additional file}

Additional file 1: Figure S1. Flow chart describing the paper retrieval and analysis strategies for this meta-analysis. GDM: gestational diabetes mellitus; CHB: chronic hepatitis B infection.
Competing interests

The authors declare that they have no competing interests.

\section{Authors' contributions}

$Y Z$ and $Y L$ conceived and coordinated the study and drafted the manuscript. DK and HL participated in the study design, reference search and data analysis. $\mathrm{WH}$ and SW participated in the study design and data extraction. DK and $\mathrm{AH}$ participated in the quality rating and data analysis. YW and YL participated in the quality rating and the data extraction and analysis. NZ supervised the statistical analysis. All authors read and approved the final manuscript.

\section{Acknowledgements}

This work was supported by National Natural Science Foundation General Program (81373065), Innovation Program of Shanghai Municipal Education Commission (14ZZO15) and the Key Discipline Construction of Public Health of Shanghai (12GWZX0101).

\section{Author details}

${ }^{1}$ Department of Epidemiology, School of Public Health, Fudan University, Shanghai 200032, China. ${ }^{2}$ The Key Laboratory on Public Health Safety, Ministry of Education, Fudan University, Shanghai 200032, China. ${ }^{3}$ Department of Clinical Laboratory, Anqing City Hospital, Anqing 246003, Anhui Province, China. ${ }^{4}$ Department of Gynaecology and Obstetrics, Anqing City Hospital, Anqing 246003, Anhui Province, China. ${ }^{5}$ Department of Biostatistics, School of Public Health, Fudan University, Shanghai 200032 China. ${ }^{6}$ Department of Sanitary Microbiology, School of Public Health, Fudan University, Shanghai 200032, China.

Received: 25 October 2013 Accepted: 4 March 2014 Published: 11 March 2014

\section{References}

1. Lavanchy D: Hepatitis B virus epidemiology, disease burden, treatment, and current and emerging prevention and control measures. J Viral Hepat 2004, 11(2):97-107.

2. Tan HH, Lui HF, Chow WC: Chronic hepatitis B virus (HBV) infection in pregnancy. Hepato int 2008, 2(3):370-375.

3. Wong $S$, Chan $L Y, Y u$ V, Ho L: Hepatitis B carrier and perinatal outcome in singleton pregnancy. Am J Perinatol 1999, 16(9):485-488.

4. Lao T, Tse KY, Chan LY, Tam KF, Ho LF: HBsAg carrier status and the association between gestational diabetes with increased serum ferritin concentration in Chinese women. Diabetes Care 2003, 26(11):3011-3016.

5. To WW, Cheung W, Mok KM: Hepatitis B surface antigen carrier status and its correlation to gestational hypertension. Aust N Z J Obstet Gynaecol 2003, 43(2):119-122.

6. Tse KY, Ho LF, Lao TT: The impact of maternal HBsAg carrier status on pregnancy outcomes: a case-control study. J Hepatol 2005, 43(5):771-775.

7. Lao T, Chan BC, Leung WC, Ho LF, Tse KY: Maternal hepatitis B infection and gestational diabetes mellitus. J Hepatol 2007, 47(1):46-50.

8. Lert-amornpong S, Caengow S, Chutaputti A: The association of pregnancy outcomes and HBsAg positive. Thai J Gastroenterol 2007, 8(3):115-118.

9. Thungsuk R: Maternal hepatitis B infection and pregnancy outcomes. J Prapokklao Hosp Clin Med Educat 2008, 25(3):246-254.

10. Saleh-Gargari S, Hantoushzadeh S, Zendehdel N, Jamal A, Aghdam H: The association of maternal HBsAg carrier status and perinatal outcome. Hepat Mon 2009, 9(3):180-184.

11. Aghamohammadi $A$, Nooritajer M: Maternal hbsag carrier and pregnancy outcome. Aust J Basic \& App/ Sci 2011, 5(3):607-610.

12. Lobstein S, Faber R, Tillmann HL: Prevalence of hepatitis B among pregnant women and its impact on pregnancy and newborn complications at a tertiary hospital in the eastern part of Germany. Digestion 2011, 83(1-2):76-82.

13. Reddick KL, Jhaveri R, Gandhi M, James AH, Swamy GK: Pregnancy outcomes associated with viral hepatitis. J Viral Hepat 2011, 18(7):e394-398.

14. Lao TT, Sahota DS, Suen SS, Law LW, Leung TY: Maternal HBsAg status and infant size-a Faustian bargain? J Viral Hepat 2012, 19(7):519-524.

15. Lu YP, Chen YP, Xiao XM, Liang XJ, Li J, Huang SM, Chen X, Hocher Berthold HB: [Impact of maternal hepatitis $B$ surface antigen carrier status on preterm 
delivery in southern China]. Nan Fang Yi Ke Da Xue Xue Bao 2012, 32(9):1369-1372

16. Lao TT, Sahota DS, Cheng YK, Law LW, Leung TY: Maternal hepatitis B surface antigen status and incidence of pre-eclampsia. J Viral Hepat 2013, 20(5):343-349

17. Mak SL, Leung KY: Hepatitis B carriers in Hong Kong: prevalence and pregnancy outomes. HKJGOM 2013, 13(1):67-73.

18. Yue DK, Molyneaux LM, Ross GP, Constantino MI, Child AG, Turtle JR: Why does ethnicity affect prevalence of gestational diabetes? The underwater volcano theory. Diabet Med 1996, 13(8):748-752

19. Crowther CA, Hiller JE, Moss JR, McPhee AJ, Jeffries WS, Robinson JS: Effect of treatment of gestational diabetes mellitus on pregnancy outcomes. N Engl J Med 2005, 352(24):2477-2486.

20. Picardi A, D'Avola D, Gentilucci UV, Galati G, Fiori E, Spataro S, Afeltra A: Diabetes in chronic liver disease: from old concepts to new evidence. Diabetes Metab Res Rev 2006, 22(4):274-283.

21. White DL, Ratziu V, El-Serag HB: Hepatitis $C$ infection and risk of diabetes: a systematic review and meta-analysis. J Hepatol 2008, 49(5):831-844.

22. Lee JG, Lee S, Kim YJ, Cho BM, Park JS, Kim HH, Cheong J, Jeong DW, Lee YH, Cho YH, Bae MJ, Choi EJ: Association of chronic viral hepatitis B with insulin resistance. World J Gastroenterol 2012, 18(42):6120-6126.

23. Li-Ng M, Tropp S, Danoff A, Bini EJ: Association between chronic hepatitis $B$ virus infection and diabetes among Asian Americans and Pacific Islanders. Dig Liver Dis 2007, 39(6):549-556.

24. Huang ZS, Huang TS, Wu TH, Chen MF, Hsu CS, Kao JH: Asymptomatic chronic hepatitis $B$ virus infection does not increase the risk of diabetes mellitus: a ten-year observation. J Gastroenterol Hepatol 2010, 25(8):1420-1425.

25. Zheng Y, Lu Y, Ye Q, Xia Y, Zhou Y, Yao Q, Wei S: Should chronic hepatitis B mothers breastfeed? A meta analysis. BMC public health 2011, 11:502

26. Wells G, Shea BO, Connell D: The Newcastle-Ottawa Scale (Nos) For Assessing The Quality Of Nonrandomized Studies In Meta-Analysis. 2010 http://www.ohri.ca/programs/clinical_epidemiology/oxford_web.ppt.

27. Greenland S: Quantitative methods in the review of epidemiologic literature. Epidemio/ Rev 1987, 9:1-30.

28. Patsopoulos NA, Evangelou E, loannidis JP: Sensitivity of between-study heterogeneity in meta-analysis: proposed metrics and empirical evaluation. Int J Epidemio/ 2008, 37(5):1148-1157.

29. Altman DG, Bland JM: Interaction revisited: the difference between two estimates. BMJ 2003, 326(7382):219.

30. Begg CB, Mazumdar M: Operating characteristics of a rank correlation test for publication bias. Biometrics 1994, 50(4):1088-1101.

31. Duval S, Tweedie R: A nonparametric "trim and fill" method of accounting for publication bias in meta-analysis. J Am Stat Assoc 2000 95(449):89-98.

32. Higgins JP, Thompson SG, Spiegelhalter DJ: A re-evaluation of randomeffects meta-analysis. J R Stat Soc 2009, 172(1):137-159.

33. Lao T, Tam KF: Maternal serum ferritin and gestational impaired glucose tolerance. Diabetes Care 1997, 20(9):1368-1369.

34. Hernan MA, Hernandez-Diaz S, Robins JM: A structural approach to selection bias. Epidemiology 2004, 15(5):615-625.

35. Higgins JP: Commentary: heterogeneity in meta-analysis should be expected and appropriately quantified. Int J Epidemiol 2008, 37(5):1158-1160

36. Kowdley KV, Belt P, Wilson LA, Yeh MM, Neuschwander-Tetri BA, Chalasani N Sanyal AJ, Nelson JE: Serum ferritin is an independent predictor of histologic severity and advanced fibrosis in patients with nonalcoholic fatty liver disease. Hepatol (Baltimore, Md) 2012, 55(1):77-85.

37. Adinolfi LE, Gambardella M, Andreana A, Tripodi MF, Utili R, Ruggiero G: Steatosis accelerates the progression of liver damage of chronic hepatitis $\mathrm{C}$ patients and correlates with specific HCV genotype and visceral obesity. Hepatol (Baltimore, Md) 2001, 33(6):1358-1364.
38. Hui JM, Sud A, Farrell GC, Bandara P, Byth K, Kench JG, McCaughan GW, George J: Insulin resistance is associated with chronic hepatitis $C$ virus infection and fibrosis progression [corrected]. Gastroenterology 2003, 125(6):1695-1704.

39. Papatheodoridis GV, Chrysanthos N, Savvas S, Sevastianos V, Kafiri G, Petraki K Manesis EK: Diabetes mellitus in chronic hepatitis B and C: prevalence and potential association with the extent of liver fibrosis. J Viral Hepat 2006 13(5):303-310

doi:10.1186/1756-0500-7-139

Cite this article as: Kong et al:: A meta-analysis of the association between gestational diabetes mellitus and chronic hepatitis B infection during pregnancy. BMC Research Notes 2014 7:139.

\section{Submit your next manuscript to BioMed Central and take full advantage of:}

- Convenient online submission

- Thorough peer review

- No space constraints or color figure charges

- Immediate publication on acceptance

- Inclusion in PubMed, CAS, Scopus and Google Scholar

- Research which is freely available for redistribution

Submit your manuscript at www.biomedcentral.com/submit
C) BioMed Central 